Conclusion In contrast to static information transfer, narrative techniques to reconstruct and reflect on recent encounters provide depth and relevance to counselling interactions, addressing multiple dimensions of HIV/STI risk experienced by MSM in Latin America.

\subsection{BEHAVIOURAL CHANGE TO REDUCE THE RISK OF PHARYNGEAL GONORRHOEA IN MEN WHO HAVE SEX WITH MEN}

Eric PF Chow, Sandra Walker, Tiffany Phillips, Christopher K Fairley. Melbourne Sexual Health Centre

\subsection{6/sextrans-2017-053264.11}

Introduction Gonorrhoea rate continues to increase at alarming rates among men who have sex with men (MSM), particularly in young MSM, in Australia and worldwide. A recent study has shown that use of antiseptic alcohol-containing mouthwash can inhibit the growth of gonorrhoea in the pharynx. The aim of this study was to examine the willingness of MSM to change their behaviours to reduce the risk of gonorrhoea.

Methods A cross-sectional questionnaire-based study was conducted among MSM attending the Melbourne Sexual Health Centre, Australia, between March and September 2015. Participants were asked how likely they would change their behaviours to reduce the risk of pharyngeal gonorrhoea. Six different strategies were asked: (1) stop tongue kissing with partners; (2) stop having receptive oral sex from partners (partner's penis in participant's mouth); (3) stop rimming partners (participant's tongue in or around partner's anus); (4) stop using saliva as lube for anal sex; (5) use condoms for oral sex; and (6) use alcohol-containing mouthwash daily.

Results A total of 926 MSM were surveyed with a median age of 29 (IQR 25-36) years. The majority of MSM $(65 \%$ [95\% CI 62\%-69\%]) expressed they were likely to use mouthwash daily to reduce the risk of pharyngeal gonorrhoea, followed by stop using saliva as lube $(63 \%$ [95\% CI $60 \%-$ 66\%]), and stop performing rimming (49\% [95\% CI 46\%$53 \%])$. In contrast, the majority of MSM (78\% [95\% CI $75 \%-80 \%])$ expressed they were unlikely to stop kissing to reduce the risk of pharyngeal gonorrhoea. Young MSM were more likely to use mouthwash daily to reduce the risk of gonorrhoea compared to older MSM.

Conclusion Men are less likely to change their sexual practices to reduce the risk of pharyngeal gonorrhoea however they are likely to use mouthwash daily to reduce the risk, particularly younger MSM.

\section{Oral Presentation Session 3}

\section{STI Prevention/Diagnosis and Community Engagement}

\subsection{AIDS PREVENTION POLICY AT SCHOOL IN BRAZIL (1994-2014) AND THE ROLE OF UNESCO}

${ }^{1}$ Luis Carlos Romero, 1,2Mariana Braga Neves, 'Maria Arebeca Otero Gomes. 'UNESCO; ${ }^{2}$ SBRASH

10.1136/sextrans-2017-053264.12
Introduction Information, values and knowledge transmitted by the school influence the lives of adolescents and young people. The school congregates a considerable proportion of this population, facilitating access to it. The objective was to analyse the evolution of the AIDS prevention policy for adolescents and young people developed in schools and the role of Unesco.

Method Documentary analysis and interviews. Interviews with health and education managers, CSOs/NGOs and stakeholders to confirm, qualify and complement information produced by documentary analysis.

Results National policy formulated in 1994: School Project (1995-2004); Health and Prevention in School Project (SPE) (2005-2007); Health in School Program (PSE) (2007-2014). Initially with a focus on prevention, the actions passed to integrate a broad set of objectives and contents of health, educational-preventive and care. Large number of schools work the themes; Low effectiveness of educational action. Availability of condoms in schools is little implemented.In the political environment, there is a resurgence of positions that are contrary to discuss sexual diversity at school with a reflection on the activities, mainly considering the interference of conservative political parties and the lobbying of Catholic and Evangelical churches with the decision-making bodies of politics and the management.

Conclusion Young people remain as one of the key populations to control the epidemic. Future of STI and AIDS prevention in litigation schools: Most managers and stakeholders believe that action should be rethought and taken up in isolation or associated with complementary strategies; Others argue that it must be replaced, because it has failed and because the school has become a barrier to young people. UNESCO had a strategic and essential role to promote the approximation of interests and articulation and cooperation between the Ministries of Health and Education.

\subsection{UNDERSTANDING SEXUAL HEALTH LANGUAGE: COMMUNITY ENGAGEMENT WITH REFUGEES FROM BURMA, POST SETTLEMENT IN AUSTRALIA}

${ }^{1}$ Amita Tuteja, ${ }^{2}$ Lena Sanci, ${ }^{3}$ Lester Mascarenhas, ${ }^{4}$ Elisha Riggs, ${ }^{3}$ Lynette 0 Dwyer, ${ }^{3}$ Di Van Villet, ${ }^{3}$ Katrina Sangster, ${ }^{3}$ Kim Mcguiness, ${ }^{2}$ Meredith Temple-Smith. ${ }^{1}$ Department of General Practice, University of Melbourne, Melbourne, Australia; ${ }^{2}$ Department of General Practice, University of Melbourne, Melbourne, Australia; ${ }^{3}$ Isis Primary Care, Hoppers Crossing, Melbourne, Australia; ${ }^{4}$ Murdoch's Children Research Institute, Royal Children's Hospital, University of Melbourne, Melbourne, Australia

\subsection{6/sextrans-2017-053264.13}

Introduction Heath care professionals (HCP) who use interpreters in reproductive health consultations with people of dissimilar cultural backgrounds often describe situations where interpreters and patients who speak the same language fail to convey intended meanings. Interpreters struggle to explain certain words, attempt to substitute taboo words or explain terms with paragraphs. This study aims to engage with refugees from Burma to critically examine the language and vocabulary of sexual health consults.

Methods Using qualitative techniques, we interviewed $27 \mathrm{HCP}$ (doctors, nurses, interpreters, social workers) involved with refugees from Burma. The interview guide drew from a conceptual framework based on principles of "humanization" of reproductive health care interlinked with ideas of "sustainable development". Interviews were audio-recorded and transcribed. 